\title{
Un Prix Goncourt original, drôle, parle de fin de vie
}

\section{Jean Martin}

Dr méd., membre de la rédaction

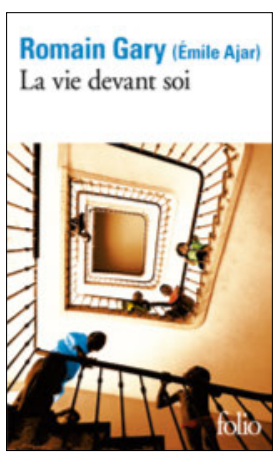

1 L'auteur (ou plutôt Momo) utilise le mot avorter pour dire euthanasier.
Emile Ajar

La vie devant soi

Paris: Mercure de France, 1975 (édition folio 2016).

274 pages. $12.10 \mathrm{CHF}$.

ISBN 978-2-070-37362-8

Romain Gary, né en Lituanie, arrive en France à 14 ans, rejoint les forces de la France libre durant la guerre, puis devient diplomate en poursuivant une carrière d'écrivain. A été le mari de l'actrice Jean Seberg. Il est le seul auteur à avoir reçu deux fois le Prix Goncourt, contre les règles de la maison; en effet, la seconde fois, est primé un livre écrit sous le pseudonyme d'Emile Ajar - après qu'il l'ait obtenu en 1956 pour Les racines du ciel.

La vie devant soi parle d'un garçon de dix ans, Mohammed dit Momo, qui vit avec Rosa, vieille dame juive, prostituée retraitée à qui il a été confié par sa mère, elle-même prostituée. Beaucoup d'humour. Ecriture originale qui séduit en prenant beaucoup de libertés avec la syntaxe et le français scolaire, pleine de formules qui font mouche. Le relisant, j’ai été frappé par le fait que Momo et sa mère adoptive - très âgée et en mauvaise santé - parlent en 1975 des sujets aujourd'hui très actuels. Notamment la fin de vie et l'euthanasie.

«Madame Rosa ne sortait presque pas. Elle n'avait plus assez de jambes et de cœur et son souffle n'aurait pas suffi à une personne le quart de la sienne [elle est très grosse]. Elle ne voulait pas entendre parler de l'hôpital où ils vous font mourir jusqu'au bout, au lieu de vous faire une piqûre. Elle disait qu'en France on était contre la mort douce et qu'on vous forçait à vivre tant que vous étiez encore capable d'en baver. Elle avait une peur bleue de la torture et disait toujours que, lorsqu'elle en aura assez, elle se fera 'avorter'.»1

Momo: "Les vieux ont la même valeur que tout le monde, même s'ils diminuent. Ils sentent comme vous et moi et même ça les fait souffrir encore plus. Mais ils sont attaqués par la nature, qui peut être une belle salope et les fait crever à petit feu. Chez nous, c'est encore plus vache que dans la nature, car il est interdit d'avorter' les vieux quand la nature les étouffe lentement.» «C'était déjà terrible de voir Madame Rosa mourir peu à peu mais, quand elle n'a plus rien d'humain, c'est quelque chose qui exige des lois pour mettre fin à ses souffrances.»

Madame Rosa: "Ils vont me faire vivre de force, c'est ce qu'ils font toujours, Momo. Ils ont des lois pour ça. C'est des vraies lois de Nuremberg. Je ne veux pas vivre plus que nécessaire. Ils vont me faire subir des sévices pour m'empêcher de mourir, ils ont un truc qui s'appelle l'Ordre des médecins qui est exprès pour ça. Ils vous en font baver jusqu'au bout et ils ne veulent pas vous donner le droit de mourir, parce que ça fait des privilégiés. J'avais un ami qui n'avait ni bras ni jambes, à cause d'un accident, et qu'ils ont fait souffrir encore dix ans pour étudier sa circulation. Je ne veux pas vivre uniquement parce que c'est la médecine qui l'exige, vivre des années dans le coma pour faire honneur à la médecine. J'ai donné mon corps à mes clients pendant trente-cinq ans, je ne vais pas maintenant le donner aux médecins.»

Momo: «Je comprendrai jamais pourquoi l'avortement [l'euthanasie] c'est seulement autorisé pour les jeunes et pas pour les vieux. Je trouve que ce type en Amérique qui a battu le record du monde comme légume [= en état végétatif], durant dix-sept ans, c'est encore pire que Jésus - parce que ça dure longtemps. C'est dégueulasse d'enfoncer la vie de force dans la gorge des gens qui ne peuvent pas se défendre et qui ne veulent plus servir.»

Intéressant de se demander, quarante ans après, par quel cheminement le jury du Goncourt a décidé de distinguer cette œuvre. Parce que, bien que le sujet ait été très tabou à l'époque, il lui paraissait important d'en débattre - ce serait surprenant à mon sens. Pour montrer qu'il pouvait choisir un ouvrage iconoclaste - avec l'argument que le style très peu académique faisait passer la provocation? Ou simplement parce que La vie devant soi avait amusé les jurés? Dans tous les cas, une lecture distrayante et tonique, mettant en scène Belleville, un quartier «différent», multiethnique, de Paris. 